\title{
O PERFIL DO CLIENTE DE CARTÕES DE CRÉDITO, NA AGÊNCIA DO SÁTÃO DA CGD
}

\author{
Pedro Coelho* \\ Paulo Almeida Pereira**
}

\begin{abstract}
Em consequência de um estágio curricular desenvolvido na agência do Sátão da Caixa Geral de Depósitos (CGD), foram recolhidas informações relevantes sobre toda a população de clientes detentores de cartões de crédito, que permitem a sua caracterização, recorrendo a técnicas de análise estatística.

Com o objectivo de verificar as diferenças entre os clientes dos dois segmentos deste produto, cartão "Classic" e "Gold", este com maior prestígio, aplicam-se técnicas de estatística descritiva para salientar as desigualdades entre os clientes dos dois produtos. $O$ método de regressão logística múltipla é utilizado para a definição do perfil dos clientes, permitindo determinar as variáveis relevantes para a atribuição desses cartões, bem como a importância relativa, de cada uma dessas variáveis significativas, para a segmentação dos clientes. O modelo também permite a previsão do tipo de cartão de cada cliente, a partir das suas características, e respectiva comparação com o cartão que efectivamente possui.
\end{abstract}

Palavras-chave: Cartões de crédito, agência do Sátão da CGD, perfil do cliente, estatística descritiva, regressão logística.

\footnotetext{
* Estagiário na Caixa Geral de Depósitos.

** Instituto Universitário de Desenvolvimento e Promoção Social - Pólo de Viseu do Centro Regional das Beiras da Universidade Católica Portuguesa.
} 


\section{CARTÕES DE CRÉDITO}

Os cartões de crédito são emitidos por instituições de crédito, devendo estas entidades elaborar as condições gerais de utilização (de acordo com as normas legais aplicáveis), das quais constarão os direitos e obrigações das entidades emitentes e dos titulares dos cartões.

A criação do cartão de crédito a nível mundial, que mais tarde veio a vulgarizar-se pela era do "dinheiro de plástico", procurou dar resposta às necessidades de uma população cada vez mais exigente e sedenta de poder procurar e utilizar todas as novas potencialidades que a sociedade moderna thes vinha proporcionando, aliando a evolução económica à evolução tecnológica e possibilitando o alargamento do negócio bancário.

Os cartões bancários surgiram nos Estados Unidos da América, na década de 60. No âmbito do sistema Bank Americard, o primeiro cartão bancário, em Portugal, foi o cartão SottoMayor, lançado em 1970 por aquele banco. Neste âmbito, a partir de 1975 vir-se-ia a adoptar a tão divulgada marca VISA.

No entanto, o grande impulso para a difusão do cartão de crédito foi a criação, em 1974, da UNICRE ${ }^{1}$, inicialmente com seis bancos accionistas e a consequente criação do cartão UNIBANCO. Tratava-se de um projecto para a criação de um cartão comum para uso internacional.

Quando foi constituída, a UNICRE dispunha já de uma rede de três mil comerciantes ${ }^{2}$, muitos dos anteriores aderentes ao cartão SottoMayor, bem como um mercado-alvo a seleccionar de entre a clientela dos seis bancos accionistas. O cartão UNIBANCO foi ganhando credibilidade, que rapidamente levou à sua grande disseminação, ainda que, inicialmente, só entre as camadas da população consideradas de gama alta/média alta.

Por motivos políticos e económicos, em 1975, foi proibida a utilização do cartão no estrangeiro, o que levou a UNICRE a ter de aderir ao sistema VISA, já que a Master Charge não contemplava a figura do cartão de âmbito local.

A UNICRE manteve até 1988 uma situação de monopólio como entidade emissora de cartões de crédito em Portugal, situação que veio a inverter-se após aquele ano, com a liberalização do mercado e a possibilidade das entidades bancárias passarem, também, a emitir cartões de crédito.

A partir de então, os bancos passaram a ser concorrentes da UNICRE, da qual eram, simultaneamente, accionistas. Esta liberalização, o incremento da concorrência entre bancos, onde avultam agora os novos 
bancos privados, o aumento do nível de vida da população, o acesso dos utentes a novos produtos bancários, veio generalizar o uso de cartões de crédito em Portugal. No final de 1996 existiam em circulação cerca de um milhão e trezentos mil cartões de crédito para um volume de negócios que rondou os cinquenta milhões de contos ${ }^{3}$.

Os bancos procuram abranger um maior número de segmentos-alvo, oferecendo aos seus clientes diversos tipos de cartões personalizados, Gold, Premier, Classic, entre outros, integrando as redes VISA, Mastercard e American Express. A oferta destes tipos de cartões faz parte da política de marketing dos bancos, visando estrategicamente a fidelização de clientes e a venda cruzada de produtos.

Um facto veio impulsionar a utilização dos cartões de crédito em Portugal: a informatização da rede comercial, que foi iniciada em 1991. Foi criada a chamada REDUNICRE, entidade responsável pela gestão e coordenação da rede de estabelecimentos que aceitam para pagamento os cartões de crédito.

Quadro I

EVOLUÇÃO DAS TRANSAÇÕES COM CARTÃO DE CRÉDITO

\begin{tabular}{lcccccc}
\hline Ano & 1991 & 1995 & 1996 & 1997 & 1998 & 1999 \\
\hline $\begin{array}{l}\text { Transações pagas com cartão } \\
\text { (milhões de transações) }\end{array}$ & 16,5 & 40,8 & 67,5 & 96,6 & 125,7 & 161,0 \\
\hline $\begin{array}{l}\text { Volume de negócios registados na rede } \\
\text { (milhões de contos) }\end{array}$ & 196 & 470 & 694 & 903 & 1183 & 1437 \\
\hline
\end{tabular}

Fonte: UNICRE - Relatório e Contas, 1999.

Entre 1991 e 1995, o volume de transações pagas com cartão teve um crescimento para mais do dobro; nos quatro anos seguintes, entre $1995 \mathrm{e}$ 1999, o crescimento aumentou para perto do quádruplo, tendo o crescimento do volume de negócios sido também significativo, mas ligeiramente inferior.

A par dos cartões de crédito, puramente bancários, em resultado da liberalização e desregulamentação dos mercados, as empresas não bancárias têm-se aventurado também na emissão destes cartões. É o caso dos clubes desportivos, Sporting e Benfica que, aproveitando a rede VISA, emitiram os seus próprios cartões de crédito e de muitas outras 
empresas que, em cooperação com uma entidade bancária, também emitiram cartões, como é o caso do Visa Universo, resultante do acordo entre uma cadeia de distribuição alimentar - Sonae - e um banco - Banco Fonsecas e Burnay, agora Banco Português de Investimento. Este foi um caso de sucesso, com mais de 200 mil cartões emitidos num curto espaço de tempo, produto de uma campanha massificada e da oferta de descontos, através do uso do cartão ${ }^{4}$.

Outras empresas têm emitido cartões de cliente que funcionam como cartões de crédito, apenas dentro das suas cadeias de vendas, o que os torna mais restritivos e condicionados. Contam-se entre estes, os cartões emitidos pela sapataria Charles, supermercados Jumbo, Multiópticas, entre outros.

\subsection{Vantagens dos cartões de crédito}

Do ponto de vista dos clientes, o cartão de crédito possibilita a compra de bens e serviços, a crédito, por parte dos seus portadores, até um determinado limite. $\mathrm{O}$ cliente realiza compras na empresa fornecedora e, em vez de fazer o pagamento em numerário ou por meio de cheque, apresenta o cartão e assina uma factura onde são reproduzidas as menções constantes do mesmo cartão.

A factura é depois remetida à sociedade gestora do cartão, que liquida as despesas efectuadas e procede à sua cobrança junto do banco emissor.

Trata-se de uma linha de crédito automática e contínua. O cliente efectua as suas compras, que liquidará mais tarde ao banco, continuando a dispor de crédito dentro do limite estabelecido (crédito revolving). Para uma melhor compreensão desta matéria, apresenta-se a Figura I. 
Figura I

ESQUEMA DE FUNCIONAMENTO DO CARTÃO DE CRÉDITO

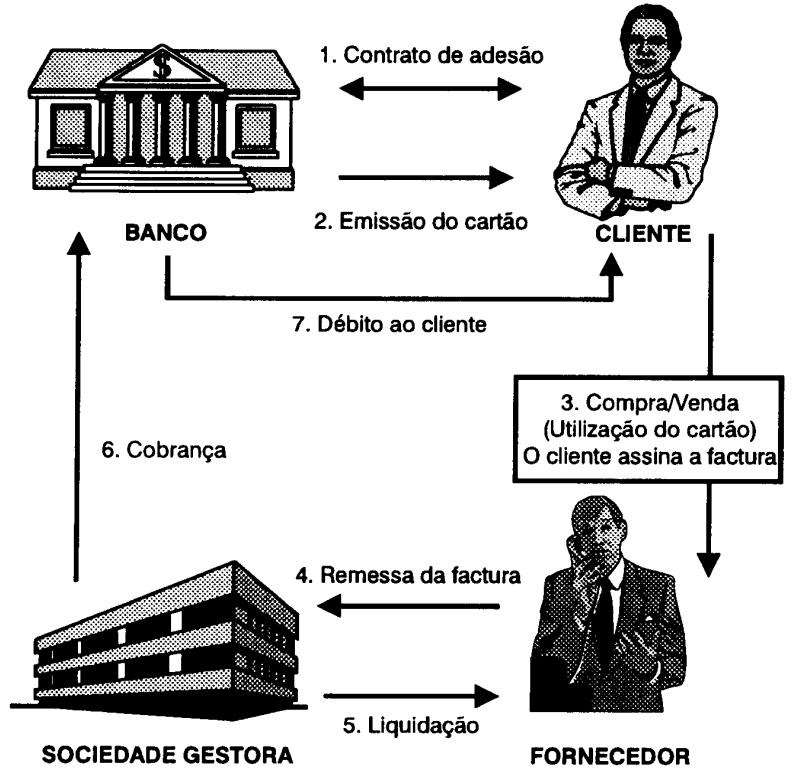

Fonte: INSTITUTO DE FORMAÇÃO BANCÁRIA (1999), Operações Bancárias Gerais I, Artes Gráficas, Lda., 20. ${ }^{a}$ Edição, 12.9 .

Do ponto de vista do Banco, o cartão de crédito afirma-se como um elemento importante da sua estratégia de marketing, junto dos melhores clientes, contribuindo para a sua fidelização e para a venda cruzada de múltiplos produtos financeiros.

Embora variando de acordo com a estratégia comercial de cada banco, os serviços (ou benefícios) associados ao cartão de crédito são geralmente:

- Seguros de saúde (só no país ou utilizáveis no estrangeiro).

- Seguros de responsabilidade civil.

- Seguros de assistência em viagem.

- Descontos.

- Etc.

Os bancos, de acordo com a sua estratégia comercial, substituem por vezes os cartões multibanco por cartões de crédito que, embora mais onerosos, têm a vantagem de possibilitar o acesso a uma linha de crédito que pode permitir, inclusive, a sua utilização no estrangeiro. 


\section{CARTÕES DE CRÉDITO DA CAIXA GERAL DE DEPÓSITOS}

Os cartões de crédito Caixa Geral de Depósitos (CGD), nomeadamente o Classic e o Gold, têm como carácter discriminatório e de atribuição dos cartões um scoring, tendo em conta o saldo médio dos últimos seis meses da conta à ordem e os rendimentos anuais líquidos auferidos pelo cliente avaliado (e não pelo agregado familiar), devidamente comprovados pelo crédito da conta à ordem, recibo de vencimento e declaração de IRS ${ }^{5}$. Ainda que se verifiquem as condições de acesso, deverá ser efectuada a análise global do cliente.

Devido a esta análise e aos custos inerentes a cada um dos cartões, o CAIXA Classic é o mais amplamente utilizado, enquanto que o CAIXA Gold responde apenas por $17 \%$ do total de cartões emitidos pela CGD.

\section{Gráfico I \\ DISTRIBUIÇÃO POR TIPO DE CARTÃO DE CRÉDITO}

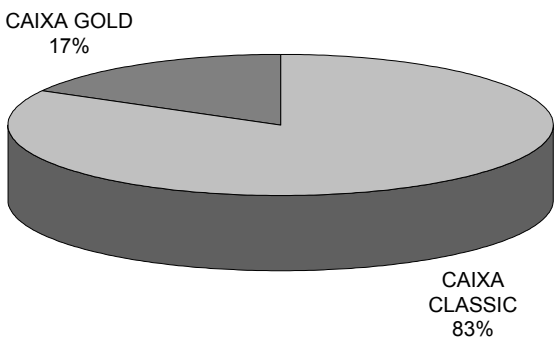

Fonte: CGD - Direcção de Marketing - Particulares.

Os cartões de crédito CGD são um meio de pagamento universal, constituindo uma excelente alternativa ao dinheiro, possibilitando o levantamento de dinheiro a crédito (cash advance), permitindo também, como sua principal função, compras de bens e serviços a crédito, em Portugal e no estrangeiro.

As transações efectuadas com estes cartões distribuem-se pelos mais diversos tipos de estabelecimentos comerciais, sendo as mais usuais realizadas nos supermercados com $22 \%$ das transações, em vestuário e calçado com $16 \%$, em restaurantes com $14 \%$ e em combustíveis com $12 \%$, como pode observar-se no Gráfico II. 


\section{Gráfico II \\ DISTRIBUIÇÃO DAS TRANSACÇÕES POR TIPO DE ESTABELECIMENTO COMERCIAL}

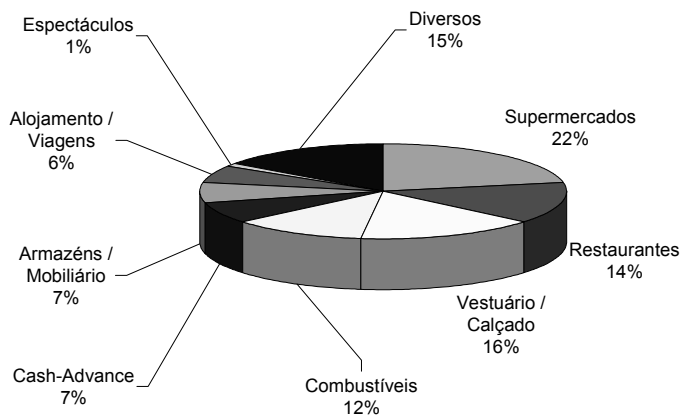

Fonte: CGD - Direcção de Marketing - Particulares.

Os cartões de crédito contêm a inscrição de alguns elementos identificativos, tais como o nome do titular, a assinatura digitalizada, o número de conta e outros de natureza diferente como, por exemplo, o prazo de validade. São um meio de pagamento personalizado, de uso pessoal e intransmissível, contendo fotografia e assinatura a laser, características que são exclusivas dos cartões CGD, contribuindo para o aumento da segurança na sua utilização e prevenção de situações fraudulentas.

Os cartões de crédito, quer o CAIXA Gold, quer o CAIXA Classic, são cartões de prestígio, que permitem aos clientes adquirir bens e serviços de uma forma simples e cómoda, dispondo de uma elevada linha de crédito renovável automaticamente. Podem ser usados, em Portugal, em mais de 38000 estabelecimentos comerciais e em toda a rede de Caixas Automáticos Multibanco. No estrangeiro, podem ser utilizados em 14 milhões de locais, na maioria dos sectores de actividade, bem como em Caixas Automáticos e Agências bancárias aderentes ao sistema VISA $^{6}$. 


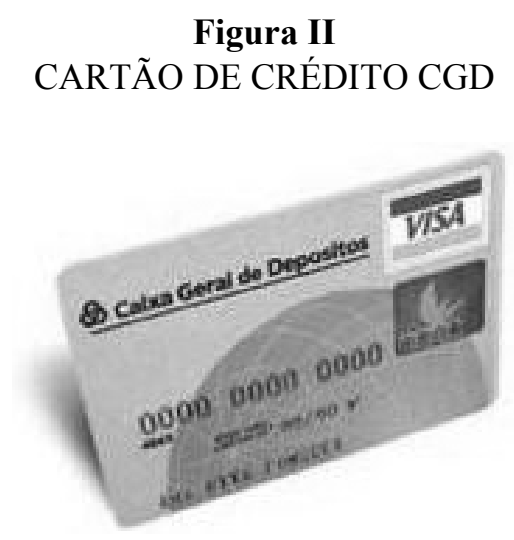

Estes cartões possuem vários serviços associados como, por exemplo, o Cartão IAPA, que permite descontos nos melhores hotéis mundiais, em empresas de Rent-a-Car, serviço de recuperação de bagagem com o sistema Bag-Guard, bem como o serviço de apoio ao cliente em viagem.

Tanto o CAIXA Gold, como o CAIXA Classic, garantem uma linha de crédito gratuita por um período de 20 até 50 dias, assim como acesso à conta à ordem na vasta rede de Caixas Automáticas privativos da CGD, assim como a realização de operações de Cash Advance (levantamento de numerário a crédito), em Portugal e no estrangeiro, nas agências bancárias que exibam o símbolo VISA. Os levantamentos de numerário a Crédito estão restritos ao limite diário de $40000 \$ 00$ em Portugal e USD ${ }^{7}$ 1000 no estrangeiro para períodos de quatro dias, sobre os quais incide a taxa de $4 \%{ }^{8}$.

Para a regularização do saldo devedor da conta-cartão, o cliente tem a opção automática, em que é debitada na sua conta à ordem pela importância total indicada no extracto mensal da conta cartão na data limite de pagamento, ou a opção mista, em que o cliente pode, quando quiser, fazer pagamentos parciais ou totais da conta cartão.

Existe também um pacote de seguros gratuito ${ }^{9}$, associado aos cartões de crédito, de que o cliente é beneficiário, em conjunto com a sua família, do qual se destacam os indicados no Quadro II.

A posse de um cartão de crédito custa ao seu titular uma anuidade. $\mathrm{O}$ montante a pagar anualmente à variável, consoante se trate de cartões de expressão mais simples, no que respeita aos plafonds e regalias inerentes, até aos que são considerados o topo de gama deste segmento de produtos. $\mathrm{O}$ crédito concedido não implica necessariamente o pagamento de juros. 
Existe um período em que estes não se aplicam e que vai geralmente até 50 dias, o que torna o produto mais aliciante.

As principais diferenças, em termos de custos de utilização, notam-se no Quadro III, referente a ambos os cartões de crédito.

\section{Quadro II \\ SEGUROS DOS CARTÕES DE CRÉDITO DA CGD}

\begin{tabular}{lll}
\hline \multicolumn{1}{c}{ Seguros } & \multicolumn{1}{c}{ CAIXA Gold } & CAIXA Classic \\
\hline Acidentes pessoais em viagem $^{10}$ & 50000 contos & 10000 contos \\
Responsabilidade civil extra-profissional $^{25000 \text { contos }}$ & 5000 contos \\
Gastos abusivos & 1000 contos/sinistro e $10000 /$ ano \\
Assistência em viagem & Pessoas e veículos & Não tem \\
Seguro de bagagem & 500 contos & Não tem \\
Assistência jurídica no estrangeiro & Tem & Não tem \\
Assistência domiciliária & Tem & Não tem \\
\hline
\end{tabular}

\section{Quadro III}

CUSTOS DE UTILIZAÇÃO DOS CARTÕES DE CRÉDITO DA CGD

\begin{tabular}{lrr}
\hline \multicolumn{1}{c}{ Custos de utilização do cartão } & CAIXA Gold & CAIXA Classic \\
\hline Anuidade do $1^{\circ}$ titular & $12750 \$ 00$ & $4500 \$ 00$ \\
Anuidade do $2^{\circ}$ titular & $5900 \$ 00$ & $1700 \$ 00$ \\
Taxa de Cash Advance (ATM ${ }^{11}$ ou Balcão) & $4 \%$ & $4 \%$ \\
Utilização na CAIXAUTOMÁTICA & gratuito & gratuito \\
\hline \multicolumn{1}{c}{ Outros custos eventuais } & & \\
\hline Colocação em lista negra urgente & $5000 \$ 00$ & $5000 \$ 00$ \\
Substituição por deterioração do cartão & $1650 \$ 00$ & $1650 \$ 00$ \\
Substituição por perda ou roubo & $1650 \$ 00$ & $1650 \$ 00$ \\
Substituição por responsabilidade da CGD & Gratuito & $6 r a t u i t o$ \\
Pedido de 2a via de extracto & $615 \$ 00$ & $615 \$ 00$ \\
Pedido de cópias de facturas nacionais & $665 \$ 00$ & $665 \$ 00$ \\
Pedido de cópias de facturas estrangeiras & $920 \$ 00$ & $920 \$ 00$ \\
\hline \multicolumn{1}{c}{ Serviço de Assistência Global Visa } & & 180,0 USD \\
Substituição de emergência do cartão: & 180,0 USD & 35,0 USD \\
Colocação em lista negra & 35,0 USD & 7,5 USD \\
Pedido de informação & 7,5 USD & \\
\hline
\end{tabular}

Fonte: $w w w . c g d . p t$ 
A diferença significativa reside, no caso dos seguros, numa maior cobertura para o cartão Gold e, para os custos, apenas no valor a pagar pela anuidade de cada cartão de crédito, quer se trate de um titular, quer se trate de dois titulares, sendo que o cartão Classic é menos dispendioso.

\section{PERFIL DOS CLIENTES DE CARTÕES DE CRÉDITO NA AGÊNCIA DO SÁTÃO DA CGD}

Após a análise das principais características dos cartões de crédito, na sua generalidade e, em particular, dos cartões emitidos pela CGD, passaremos a apresentar um estudo sobre o perfil dos clientes que detêm cartões de crédito, na agência do Sátão da CGD. Esta análise passa pela recolha e tratamento estatístico da informação relevante disponível sobre os referidos clientes, tratando a totalidade da população em causa, em que cada unidade é constituída por um cliente possuidor de um cartão de crédito. Devido ao sigilo exigido, a forma como são apresentados os dados estatísticos está, muitas das vezes, condicionada apenas a valores relativos que, pensamos, serão suficientes para a definição do perfil em causa. Todos os dados estatísticos foram recolhidos no decorrer do mês de Janeiro de 2001, sendo tratados com o auxílio do software informático SPSS - Statistical Package for Social Sciences (Pestana e Gageiro, 1998).

\subsection{Caracterização dos clientes de cartões de crédito}

Importa, antes de uma análise estatística que permita estudar as diferenças entre os clientes com cartões Classic e Gold, caracterizar a população total em estudo, ou seja, todos os clientes de cartões de crédito desta agência.

Os gráficos apresentados ilustram esta caracterização. 


\begin{abstract}
Gráfico III
CONCELHO DO LOCAL DE RESIDÊNCIA E CLASSES ETÁRIAS
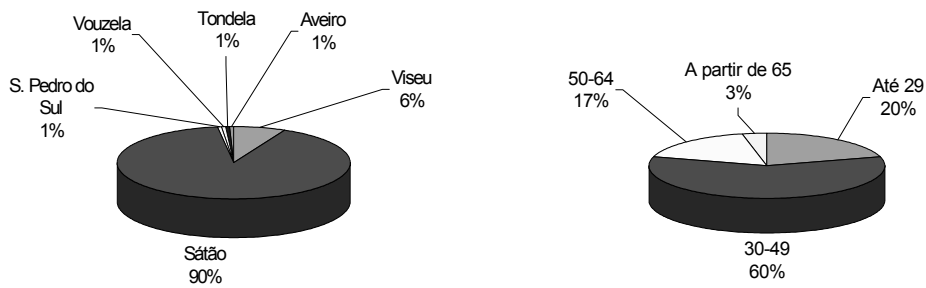

A grande maioria dos clientes - 73\% - é do sexo masculino, demonstrando a tendência para apenas o elemento do sexo masculino do casal deter cartão de crédito; como seria de esperar, a quase totalidade reside no concelho do Sátão; no que respeita à idade, a classe etária predominante tem entre 30 e 49 anos, com $60 \%$ dos clientes, seguida pelos jovens até 29 anos, com $20 \%$, o que sugere que este meio de pagamento é utilizado quando se atinge um período da vida já com certa estabilidade financeira, tendo também uma importante penetração nas camadas mais jovens.
\end{abstract}

\title{
Gráfico IV
}

ESTADO CIVIL E HABILITAÇÕES LITERÁRIAS
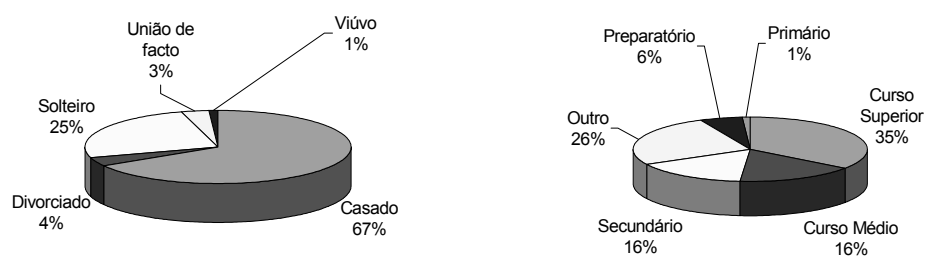

A maioria dos clientes são casados, existindo também um grupo significativo de solteiros, o que está directamente relacionado com as classes etárias; quanto às habilitações, mais de metade dos clientes têm um curso médio ou superior, pelo que a formação académica é um factor 
relevante neste segmento, pela predisposição e facilidade na utilização dos cartões e, também, por gerar maiores rendimentos.

Pode referir-se que a maioria dos clientes possui habitação própria, $42 \%$ sem hipoteca e $27 \%$ com hipoteca, vivendo $22 \%$ em casa de familiares e $8 \%$ em habitação arrendada.

\section{Gráfico V \\ SITUAÇÃO E CATEGORIA PROFISSIONAL}
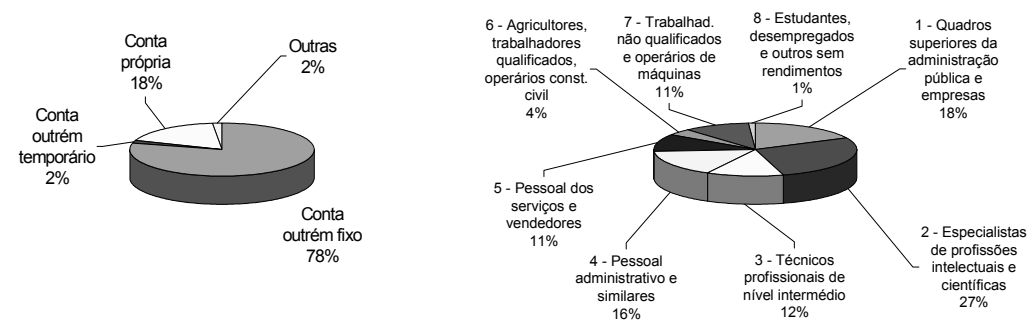

A situação profissional dos clientes deste produto é estável, na grande maioria por conta de outrem, estando alguns também por conta própria. Quanto à categoria profissional, de acordo com a Classificação Nacional de Profissões, elaborada em 1994, pelo Instituto de Emprego e Formação Profissional (IEFP, 1994), os grupos com maiores rendimentos (quadros superiores e especialistas das profissões intelectuais e científicas) são os mais representativos.

\section{Gráfico VI}

PATRIMÓNIO E RENDIMENTO TOTAL
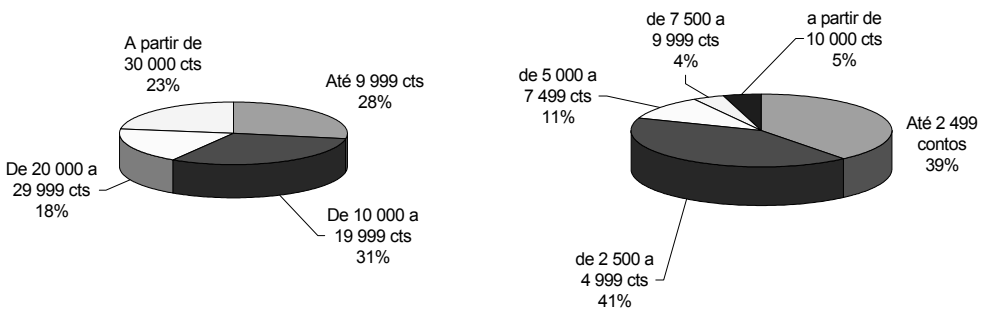

No primeiro gráfico, verifica-se uma distribuição muito pouco heterogénea entre as classes patrimoniais definidas; quanto aos 
rendimentos, a grande maioria apresenta rendimentos inferiores a 5000 contos anuais, o que é comum para uma pessoa residente num concelho do interior.

Um outro dado relevante sobre estes clientes é o facto de $11 \%$ deles possuírem, pelo menos, outro cartão de crédito.

\subsection{Caracterização dos segmentos Classic e Gold}

No total de clientes estudado, $74 \%$ possuem cartões CAIXA Classic e $26 \%$ CAIXA Gold, sendo de notar que a frequência relativa dos clientes com o cartão de maior prestígio é consideravelmente superior à média global da CGD.

\section{Gráfico VII}

CLIENTES CAIXA GOLD E CLASSIC NA AGÊNCIA DO SÁTÃO

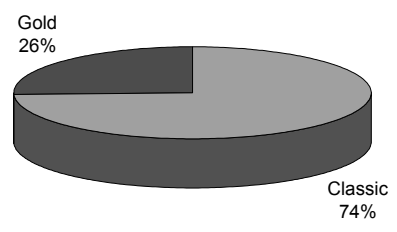

De seguida, procede-se à análise comparativa destes clientes dos dois tipos de cartões de crédito, na agência do Sátão da CGD, de forma a verificar quais as variáveis relevantes para a atribuição dos cartões Classic ou Gold.

Confirmando os dados anteriores sobre a predominância de clientes do sexo masculino, verifica-se que essa tendência se mantém para o cartão Gold, talvez devido ao facto de ser uma zona rural, em que o elemento masculino gere as contas familiares, com as esposas mais ocupadas com actividades domésticas; tal como seria de esperar, as classes etárias mais elevadas apresentam uma maior frequência também neste tipo de cartão, possivelmente devido à estabilidade na vida social e profissional. Note-se que nenhum jovem com menos de 30 anos tem cartão Gold, talvez pelo seu maior custo. 


\section{Gráfico VIII}

\section{CLIENTES GOLD E CLASSIC POR GÉNERO E CLASSES ETÁRIAS}
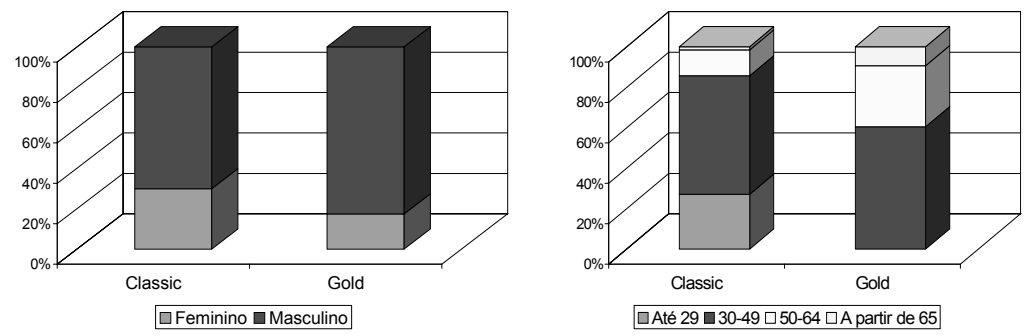

Relacionado, certamente, com o aspecto anterior, está o estado civil dos clientes, verificando-se que, para o cartão Classic, 31\% dos clientes são solteiros e $59 \%$ são casados, enquanto que os utilizadores de cartão Gold são, na grande maioria - $87 \%$ - casados, contra apenas $9 \%$ solteiros.

A residência domiciliar é semelhante para os clientes de ambos os cartões, quase na totalidade no concelho do Sátão.

Quanto às habilitações académicas, o curso superior é bastante mais comum nos clientes com cartões Gold, ocorrendo diminuição da frequência de formações ao nível básico e secundário.

Os clientes de cartão Gold habitam, quase na totalidade, em casa própria, a maioria já sem qualquer hipoteca. A habitação em casa de familiares ocorre, principalmente, com os clientes de cartões Classic, o que sugere que a atribuição do cartão de maior prestígio é para o casal de cada agregado familiar.

\section{Gráfico IX}

CLIENTES GOLD E CLASSIC POR HABILITAÇÕES LITERÁRIAS E TIPO DE HABITAÇÃO
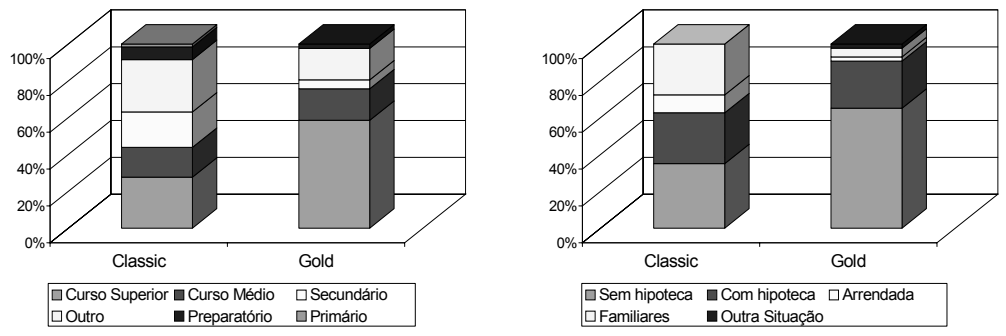
Relativamente à actividade profissional, as diferenças entre os clientes dos dois tipos de cartões são significativas: os clientes com cartões Gold são, na grande maioria, quadros superiores ou especialistas de profissões intelectuais e científicas; a diversidade de profissões é bastante superior no cartão Classic, embora os dois grupos anteriores ainda tenham um peso relevante.

\section{Gráfico X}

CLIENTES GOLD E CLASSIC POR ACTIVIDADE PROFISSSIONAL

Classic

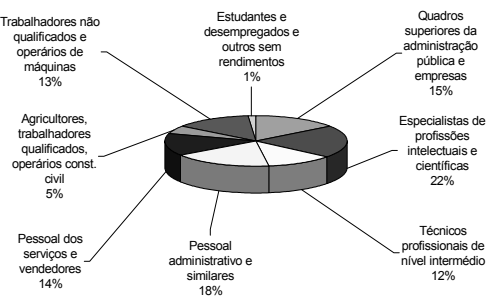

Gold

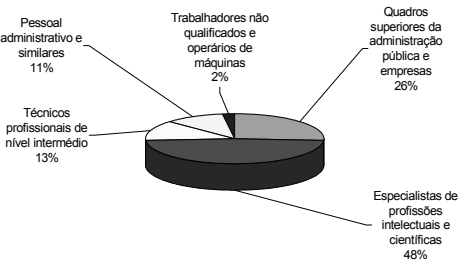

Deve referir-se que os clientes com cartão Gold detêm, com maior frequência $(20 \%)$, um outro cartão de crédito bancário, percentagem que é de apenas 7\% no grupo dos clientes com cartão Classic.

Quanto ao património e rendimento totais, sucede o que seria de esperar: os clientes pertencentes às classes com valores superiores de património e rendimento predominam no cartão Gold, acontecendo precisamente o inverso para os clientes com cartão Classic.

\section{Gráfico X}

CLIENTES GOLD E CLASSIC POR PATRIMÓNIO E RENDIMENTO

Património total

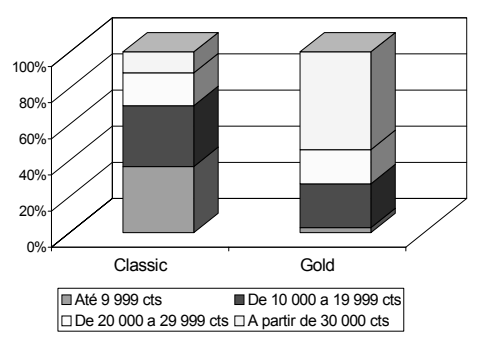

Rendimento total

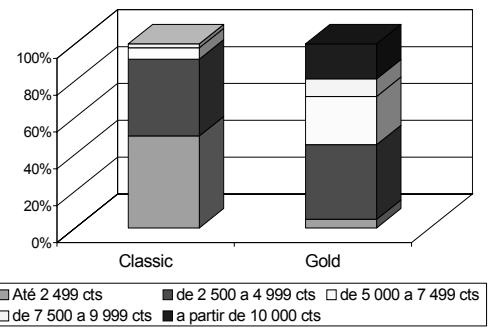


Através de uma análise global aos dados estatísticos analisados, podem caracterizar-se os clientes pertencentes a cada um dos segmentos deste produto, como se passa a apresentar no Quadro IV, o que poderá ser relevante, por exemplo, para a definição de estratégias de marketing diferenciadas dirigidas aos clientes de cartões de crédito CAIXA Classic e Gold, bem como a possíveis potenciais clientes.

\section{Quadro IV}

SEGMENTAÇÃO DOS CLIENTES DE CARTÕES DE CRÉDITO

\begin{tabular}{ll}
\hline \multicolumn{1}{c}{ CAIXA Classic } & \multicolumn{1}{c}{ CAIXA Gold } \\
\hline Maioritariamente do sexo masculino & Maioritariamente do sexo masculino \\
\hline Idade inferior a 49 anos & Idade superior a 30 anos \\
\hline $\begin{array}{l}\text { Profissões intelectuais e científicas; } \\
\text { Quadros superiores; }\end{array}$ & $\begin{array}{l}\text { Profissões intelectuais e científicas; } \\
\text { Pessoal administrativo e similares; }\end{array}$ \\
$\begin{array}{l}\text { Quadros superiores; } \\
\text { Trabicos, pessoal administrativo, }\end{array}$ & $\begin{array}{l}\text { Pessoal administrativo e técnicos } \\
\text { profissionais (com menor peso) }\end{array}$ \\
pessoal dos serviços. & \\
Curso médio, superior ou secundário. & Curso médio ou superior. \\
\hline Habitação própria ou de familiares & Habitação própria \\
\hline Património até 20000 contos. & $\begin{array}{l}\text { Património superior a } 10000 \text { contos, em } \\
\text { especial a partir de } 30000 \text { contos. }\end{array}$ \\
\hline Rendimentos até 5000 contos. & Rendimentos superiores a 2500 contos. \\
\hline
\end{tabular}

\section{APLICAÇÃO DO MÉTODO DE REGRESSÃO LOGÍSTICA À ANÁLISE DOS SEGMENTOS DOS CARTÕES DE CRÉDITO}

A caracterização, através de métodos estatísticos puramente descritivos é importante para, como a própria designação sugere, conhecer a população em análise, neste caso, os clientes com cartões de crédito da CGD, na agência do Sátão e o seu perfil. No entanto, este estudo pode ser complementado com outras formas de análise.

Devido às peculiaridades das variáveis em análise, torna-se possível a aplicação de métodos de regressão logística (Neter et al., 1996) que relacionam uma variável dependente qualitativa, dicotómica ou binária, 
com dois resultados possíveis - cliente com cartão Classic ou Gold -, com outras variáveis independentes, que contribuem para a definição do perfil de cada um dos segmentos de cartões de crédito, variáveis essas correspondentes às previamente analisadas por métodos de estatística descritiva no ponto anterior.

\subsection{Modelo de regressão logística}

Sendo a variável dependente representada por $Y$, as variáveis independentes por $X_{i}$ e os parâmetros que relacionam a primeira com as segundas, pelas letras do alfabeto grego $\beta$, o modelo de regressão logística múltipla pode ser apresentado na seguinte forma:

$$
\beta^{\prime} X=\beta_{0}+\beta_{1} X_{1}+\beta_{2} X_{2}+\cdots+\beta_{p-1} X_{p-1}
$$

em que a função de resposta logística múltipla permite calcular o valor esperado da variável dependente $-E(Y)$-, através de:

$$
E(Y)=\frac{\exp \left(\beta^{\prime} X\right)}{1-\exp \left(\beta^{\prime} X\right)}=\left[1+\exp \left(-\beta^{\prime} X\right)\right]^{-1}
$$

(exp - função exponencial)

A função de resposta:

$$
\text { (3) } \quad E\left(Y_{i}\right)=\pi_{i}
$$

dá-nos a probabilidade (que varia entre um valor nulo e a unidade) da variável de resposta tomar o valor um, para determinados valores das variáveis independentes.

Importa definir o significado dos parâmetros do modelo $\left(\beta_{1}, \beta_{2}, \ldots, \beta_{p-1}\right)$. A interpretação de $\beta_{i}$ é dada por: o aumento de uma unidade na variável $X_{i}$, mantendo as restantes variáveis constantes, provoca que a razão entre as probabilidades $\pi_{i} /\left(1-\pi_{i}\right)$ seja multiplicada por $\exp \left(\beta_{i}\right)$.

A partir de uma amostra, constituída por observações das variáveis, calculam-se as estimativas dos parâmetros do modelo, utilizando o método da máxima verosimilhança. $\mathrm{O}$ valor de cada parâmetro $\beta_{i}$ é estimado pelo estimador $b_{i}$.

O modelo permite verificar a existência de diferenças entre o valor previsto para a variável de resposta (calculado em função da probabilidade) e o realmente observado e, além disso, possibilita a definição das variáveis independentes relevantes para o modelo, bem como a sua importância relativa. 


\subsection{Variáveis utilizadas no modelo}

A variável dependente, ou de resposta, consiste no tipo de cartão de crédito de cada cliente. A variável dependente é representada pelos valores zero e um para as duas classes que a constituem, ou seja:

- $\mathrm{Y}=0 \rightarrow$ Cliente com cartão de crédito Classic;

- $\mathrm{Y}=1 \rightarrow$ Cliente com cartão de crédito Gold.

As variáveis independentes resultam das estatísticas analisadas no ponto 3. que, sendo dados quantitativos, são representadas em escala absoluta ou, no caso de dados qualitativos, podem ser classificadas numa escala ordinal.

As variáveis quantitativas utilizadas são a idade (em anos), o rendimento total (em milhares de contos) e o património total (também em milhares de contos).

Como variáveis qualitativas, em escala ordinal, são analisadas o sexo, as habilitações literárias, o tipo de habitação, a situação profissional e a categoria da actividade profissional, de acordo com as classes ordenadas definidas no Quadro V. Note-se que as diferentes variáveis estão divididas em classes que apresentam uma relação ordinal, entre si. Por exemplo, as classes das habilitações são apresentadas por ordem crescente de nível de ensino.

\section{Quadro V}

\section{CLASSES DAS VARIÁVEIS INDEPENDENTES QUALITATIVAS}

\begin{tabular}{|c|c|c|c|}
\hline Sexo & Habilitações & Tipo de habitação & Situação profissional \\
\hline 0-Feminino & 0-Primária & 0-Outra & $0-$ Outra \\
\hline \multirow[t]{5}{*}{ 1-Masculino } & 1-Preparatório & 1-Familiares & 1-Temporário \\
\hline & 2-Outro & 2-Arrendada & 2-Conta outrem fixo \\
\hline & 3-Secundário & 3-Própria c/ hipoteca & 3-Conta própria \\
\hline & 4-Curso médio & 4-Própria s/ hipoteca & \\
\hline & 5-Curso superior & & \\
\hline
\end{tabular}

Categoria profissional

1 - Quadros superiores da administração pública e empresas

2 - Especialistas de profissões intelectuais e científicas

3 - Técnicos profissionais de nível intermédio

4 - Pessoal administrativo e similares

5 - Pessoal dos serviços e vendedores

6 - Agricultores, trabalhadores qualificados, operários construção civil

7 - Trabalhadores não qualificados e operários de máquinas

8 - Estudantes, desempregados e outros sem rendimentos 
Recorrendo à utilização das variáveis apresentadas, o modelo permite, portanto, calcular a probabilidade de um cliente possuir cartão de crédito Gold, a partir dos dados que o caracterizam, possibilitando a verificação de existência de disparidades na segmentação e, além disso, a definição das variáveis relevantes para a segmentação dos clientes, relativamente aos dois tipos de cartão, bem como a sua importância relativa.

\subsection{Construção do modelo de regressão logística}

Para proceder à aplicação do modelo de regressão logística a esta análise do perfil do cliente, com as características de um estudo observacional explicativo, apenas se utilizam as observações (leia-se clientes) que apresentam dados, para todas as variáveis. Os restantes consideram-se casos omissos (missing values), que são descartados da elaboração do modelo: estes correspondem a $26 \%$ do número total de clientes.

O primeiro passo na construção do modelo consiste na selecção das variáveis independentes, com relevância para a explicação da variável dependente, a incluir no modelo. Deste modo, elaborou-se um modelo em se explica o tipo de cartão de crédito através dos dados que caracterizam os clientes (oito variáveis independentes), cujos resultados mais importantes são apresentados no Quadro VI.

Quadro VI

SELECÇÃO DAS VARIÁVEIS A INCLUIR NO MODELO

\begin{tabular}{lrlcc}
\hline \multicolumn{1}{c}{ Variável i } & $b_{i}$ & $\begin{array}{c}\text { Desvio } \\
\text { padrão }\end{array}$ & $\begin{array}{c}\text { Valor de } \\
\text { prova }\end{array}$ & exp $\left(b_{i}\right)$ \\
\hline Sexo & 1,173 & 0,741 & 0,114 & 3,230 \\
Idade & 0,049 & 0,034 & 0,144 & 1,050 \\
Habilitações & 1,014 & 0,405 & 0,012 & 2,757 \\
Tipo de habitação & 0,104 & 0,322 & 0,748 & 1,109 \\
Situação profissional & 1,185 & 1,220 & 0,331 & 3,271 \\
Rendimento total & 0,406 & 0,163 & 0,013 & 1,501 \\
Património total & 0,034 & 0,022 & 0,119 & 1,034 \\
Categoria profissional & $-0,572$ & 0,288 & 0,047 & 0,564 \\
Constante & $-11,881$ & 4,812 & 0,014 & \\
\hline
\end{tabular}


Para o objectivo da selecção das variáveis relevantes, deve analisar-se o seu valor de prova, que representa, de uma forma simplista, a probabilidade de uma variável não ser importante para o modelo. As variáveis menos relevantes para explicar o tipo de cartão dos clientes são o tipo de habitação e a situação profissional, que serão eliminadas, originando a construção de um novo modelo. Os restantes dados apresentados para o modelo de regressão logística múltipla serão descritos para o novo modelo - Quadro VII -, sendo a sua análise semelhante para o quadro anterior.

No novo modelo desenvolvido, as variáveis com maior valor de prova são o sexo e a idade, que ainda assim não são passíveis de ser excluídas do modelo, uma vez que a probabilidade de não serem significativas ronda, para ambas, apenas os $13 \%$.

Quadro VII

MODELO DE REGRESSÃO LOGÍSTICA

\begin{tabular}{lclcc}
\hline \multicolumn{1}{c}{ Variável i } & $b_{i}$ & $\begin{array}{c}\text { Desvio } \\
\text { padrão }\end{array}$ & $\begin{array}{c}\text { Valor de } \\
\text { prova }\end{array}$ & $\exp \left(b_{i}\right)$ \\
\hline Sexo & 1,102 & 0,728 & 0,130 & 3,010 \\
Idade & 0,047 & 0,032 & 0,136 & 1,048 \\
Habilitações & 0,734 & 0,271 & 0,007 & 2,083 \\
Rendimento total & 0,372 & 0,152 & 0,014 & 1,451 \\
Património total & 0,040 & 0,022 & 0,070 & 1,041 \\
Categoria profissional & $-0,639$ & 0,272 & 0,019 & 0,528 \\
Constante & $-7,553$ & 2,082 & 0,000 & \\
\hline
\end{tabular}

As variáveis significantes para a definição do tipo de cartão (Gold ou Classic) de cada cliente, ou seja, a segmentação dos clientes neste produto, são o sexo, a idade, as habilitações literárias, o rendimento, o património e a categoria profissional, de acordo com a forma como foram definidas e categorizadas em classes.

Importa agora explicar a importância de cada uma destas variáveis na definição do tipo de cartão, para o que é relevante observar a última coluna do quadro anterior. A probabilidade de um cliente ter cartão Gold aumenta, pelos valores apresentados nesta coluna, quando a variável em análise aumenta uma unidade, mantendo todas as restantes variáveis constantes.

Por exemplo, para a primeira variável "sexo", a probabilidade de um cliente do sexo masculino ter cartão Gold é aproximadamente três vezes superior à de uma cliente do sexo feminino. Relativamente à idade do 
cliente, à medida que aumenta um ano, a probabilidade de ele ter cartão Gold aumenta 4,8\%. Para cada nível superior de habilitações literárias, a probabilidade de ter cartão Gold aumenta para mais do dobro $(2,083)$. No que diz respeito ao rendimento total e património total, um aumento de mil contos provoca aumentos na probabilidade de ter cartão Gold de $45,1 \%$ e $4,1 \%$, respectivamente, pelo que o aumento no rendimento (em valores absolutos) é mais relevante para a atribuição deste tipo de cartão. Finalmente, para a variável categoria profissional, à medida que se passa para uma classe definida com um valor superior, a probabilidade de ter cartão Gold diminui para aproximadamente metade $(0,528)$; deve aqui salientar-se que as categorias profissionais das classes com menor numeração, conforme definidas no Quadro V, são as categorias melhor remuneradas

Note-se que a análise efectuada, a cada uma das variáveis, é válida individualmente, mantendo constantes os valores das restantes variáveis e que os valores de probabilidade apresentados para a alteração de uma unidade nas variáveis independentes são valores médios, que podem não se aplicar uniformemente em toda a gama da variável, ou em todas as classes definidas.

\subsection{Previsões com o modelo de regressão logística}

O modelo de regressão logística múltipla desenvolvido, permite ainda efectuar as previsões do tipo de cartão que cada cliente deveria ter, de acordo com os dados estatísticos disponíveis e compará-lo com o tipo de cartão que efectivamente tem, cujos resultados se apresentam no Quadro VIII.

Quadro VIII

PREVISÕES DO TIPO DE CARTÃO

\begin{tabular}{ccc}
\hline & \multicolumn{2}{c}{ Tipo de cartão previsto } \\
\cline { 2 - 3 } Tipo de cartão observado & Classic & Gold \\
\hline Classic & $94,9 \%$ & $5,1 \%$ \\
Gold & $25,7 \%$ & $74,3 \%$ \\
\hline
\end{tabular}

Do total de clientes com cartão Classic, o modelo estima que, apenas para $5,1 \%$ deles, deveriam ter cartão Gold, enquanto que, do total de clientes com cartão Gold, é estimado que $25,7 \%$ deles deveriam ter o 
cartão Classic. Estas diferenças nos valores previstos pelo modelo devem-se a variáveis não contempladas por aquele e que têm importância para a definição do tipo de cartão a atribuir. Para a globalidade dos clientes analisados, o modelo desenvolvido consegue prever correctamente o tipo de cartão possuído em $89,5 \%$ dos casos.

\section{CONCLUSÃO}

O estudo aqui apresentado surge como corolário de um estágio curricular, da licenciatura em Gestão e Desenvolvimento Social, que teve lugar na agência do Sátão da CGD, cujo mérito residiu na recolha sistemática dos dados necessários, durante o mês de Janeiro de 2001, para o desenvolvimento desta análise.

Salienta-se, mais uma vez, a significativa colaboração que a Universidade Católica Portuguesa, nomeadamente o seu Pólo de Viseu e, mais especificamente, o curso de licenciatura em Gestão e Desenvolvimento Social ministrado no âmbito do Instituto Universitário de Desenvolvimento e Promoção Social, mantém com esta prestigiada instituição bancária, que é bastante meritória, nos mais variados aspectos, entre eles, o desenvolvimento de colaborações como a aqui apresentada. Não queremos, por esse motivo, deixar de prestar um bem haja especial à agência do Sátão e à Direcção Regional da CGD.

Este trabalho permitiu caracterizar o perfil dos dois segmentos de clientes de cartões de crédito na agência em análise, com uma ampla descrição do perfil dos detentores de cartões Classic e Gold, recorrendo a técnicas de estatística descritiva e à regressão logística múltipla.

\section{NOTAS}

${ }^{1}$ UNICRE - Cartão Internacional de Crédito, S.A.

${ }^{2}$ Cf. CAIXA GERAL DE DEPÓSITOS - Direcção de Marketing - Particulares.

${ }^{3}$ Idem.

${ }^{4}$ Cf. CAIXA GERAL DE DEPÓSITOS - Direcção de Marketing - Particulares.

${ }^{5}$ IRS - Imposto sobre o Rendimento das Pessoas Singulares.

${ }^{6}$ Cf. CAIXA GERAL DE DEPÓSITOS - Guia do Utilizador - CAIXA

Gold e Classic, p. 3. 
${ }^{7}$ USD - Dólares dos Estados Unidos da América.

${ }^{8}$ Cf. CAIXA GERAL DE DEPÓSITOS - Guia do Utilizador - CAIXA Gold e Classic, p. 13.

${ }^{9}$ Idem, p. 48.

${ }^{10}$ A cobertura está sempre activa, independentemente da compra do título de viagem ser adquirido, ou não, com o cartão de crédito.

${ }^{11}$ ATM - Automated Teller Machine.

\section{BIBLIOGRAFIA}

BORGES, António, et al. (1995), Elementos da Contabilidade Geral, 14ª Edição, Editora Rei dos Livros, Lisboa.

CAIXA GERAL DE DEPÓSITOS: Caderno Comercial.

CAIXA GERAL DE DEPÓSITOS: Direcção de Marketing - Particulares.

CAIXA GERAL DE DEPÓSITOS: Guia do Utilizador - CAIXA Gold e Classic.

CAIXA GERAL DE DEPÓSITOS (1998), Relatório e Contas 97, Caixa Geral de Depósitos, Lisboa.

CAIXA GERAL DE DEPÓSITOS (1999), Relatório e Contas 98, Caixa Geral de Depósitos, Lisboa.

CAIXA GERAL DE DEPÓSITOS (2000), Relatório e Contas 99, Caixa Geral de Depósitos, Lisboa.

DIÁRIO DA REPÚBLICA - I SÉRIE - A, (1993), n. ${ }^{\circ}$ 195, Decreto Lei n. ${ }^{\circ}$ 287/93, de 20 de Agosto.

IEFP - INSTITUTO DO EMPREGO E FORMAÇÃO PROFISSIONAL (1994), Classificação Nacional de Profissões, Edição: Instituto do Emprego e Formação Profissional, Ministério do Emprego e Segurança Social, Lisboa.

FERREIRA, J. M. Carvalho et al. (1996), Psicossociologia das Organizações, Editora McGraw - Hill, Alfragide.

FREIRE, Adriano, (1997), Estratégia - Sucesso em Portugal, Editorial Verbo, Lisboa.

LENDREVIE, Jacques, et al. (1996), Mercator - Teoria e Prática do Marketing, $6^{\mathrm{a}}$ Edição, Publicações Dom Quixote, Lisboa.

MOREIRA, José António Cardoso, (1998), Análise Financeira de Empresas: da Teoria à Prática, $2^{\mathrm{a}}$ Edição, Associação da Bolsa de Derivados do Porto, Porto. 
NETER, J.; KUTNER, M. H.; NACHTSHEIM, C. J.; WASSERMAN, W. (1996), Applied Linear Statistical Models, Fourth Edition, Irwin, Chicago, p. 567608.

PALHAÇA, Fernando, et al. (1999), Operações Bancárias Gerais I, Artes Gráficas, Ld. ${ }^{\text {a }}$, Lisboa.

PeSTANA, M. H., GAGEIRO, J. N. (1998), Análise de dados para Ciências Sociais - A Complementaridade do SPSS, Edições Sílabo, Lisboa.

UNICRE, CARTÃO INTERNACIONAL DE CRÉDITO, S.A. (2000), Relatório e Contas 1999, (1999), Unicre, Lisboa.

Internet: $w w w . c g d . p t$ 